\title{
CDISC SEND Trial Summary Parameter Long Name Terminology
}

National Cancer Institute

\section{Source}

National Cancer Institute. CDISC SEND Trial Summary Parameter Long Name

Terminology. NCl Thesaurus. Code C90007.

The terminology that includes concepts relevant to the Clinical Data Interchange Standards Consortium (CDISC) Standard for the Exchange of Non-clinical Data (SEND) trial summary parameters. 